http://jmscr.igmpublication.org/home/ ISSN (e)-2347-176x ISSN (p) 2455-0450

crossref DOI: https://dx.doi.org/10.18535/jmscr/v7i8.80

\author{
Journal Of Medical Science And Clinical Research \\ IGM Publication \\ An official Publication of IGM Publication
}

\title{
Predictive power of Serum C-reactive protein in the Prognostication of Acute Pancreatitis
}

\author{
Authors \\ Rakesh Praveen Raj M.R. ${ }^{1}$, Reeja R. ${ }^{2 *}$ \\ ${ }^{1}$ Professor, Department of General surgery, Azeezia Institute of Medical Sciences \& Research, Kollam India \\ Corresponding Author \\ Reeja R. \\ ${ }^{2}$ Associate Professor, Department of Pharmacology, Govt. Medical College, Kollam, India
}

\begin{abstract}
Background: The assessment of severity in acute pancreatitis is very important as $20 \%$ of cases can progress to serious life-threatening events. Several multifactorial scoring systems are widely used; but they are too cumbersome to use in daily clinical practice. A single test which has a predictive power of prognostication is serum $C$-reactive protein.

Aims: To assess the relative accuracy of serum $C$-reactive protein and Ranson's scoring system in predicting the severity of acute pancreatitis. To evaluate the accuracy of serum $C$-reactive protein in monitoring the clinical course of the disease

Materials and Methods: it is a prospective study done on all patients admitted in the institution over a period of one year, who were diagnosed with acute pancreatitis.

Results: A total of 42 patients were studied. Thirty patients had mild acute pancreatitis and 12 had severe. Ranson's criteria predicted 16 patients to have severe pancreatitis, whereas only 8 cases turned out to be severe. CRP estimation predicted 14 to be severe, of which, 10 patients had a severe outcome. Ranson's criteria showed a sensitivity of 66.6\%; specificity of $73.3 \%$ and accuracy of 71.4 ; whereas, serum CRP showed a sensitivity of 83.3 ; specificity of $86.6 \%$ and accuracy of $85.7 \%$.

Conclusion: Serum CRP shows a higher prognostic sensitivity and accuracy than Ranson's scoring system. $C R P$ as a single parameter can be used to predict the development of complications in acute pancreatitis. It is a good early marker for the severity of acute pancreatitis. The CRP value at the end of the first week is useful in monitoring the clinical course.
\end{abstract}

Keywords: Acute pancreatitis, Ranson's criteria, Serum C-reactive protein,Severe acute pancreatitis.

\section{Introduction}

Acute pancreatitis (AP) is a potentially serious and life-threatening condition. In most patients (80$85 \%$ ), the course is mild and self-limiting; in the remaining $20 \%$, however, the disease is severe and often fulminant and is associated with organ failure and significant morbidity and mortality. Accordingly, mortality rates for acute pancreatitis vary widely, ranging from $1 \%$ to $3 \%$ in mild uncomplicated disease, to $13-35 \%$ in severe pancreatitis $^{[1],[2]}$. Early prediction of severe disease should identify patients who are at risk of adverse outcome from acute pancreatitis ${ }^{[3]}$. Furthermore, a predictor, able to assist in monitoring the course of a patient during an episode of acute pancreatitis, would be highly useful ${ }^{[4]}$. Multiple- factor scoring systems like Ranson's and Glasgow criteria have been widely used in the study of patients with acute pancreatitis, for stratification of the risk of death or 
major morbidity. The inability to obtain a complete score until at least 48 hours into the illness and the complexity of the scoring system itself, limits their routine use in daily clinical practice. Neither can they be applied sequentially to monitor the course of the attack which might usefully assess the response to therapy or provide warning of a developing late complication. Although Ranson's criteria have been widely used, there is no single indicator to predict the outcome of acute pancreatitis. The ideal marker for identifying patients with severe acute pancreatitis would have high sensitivity and positive predictive value ${ }^{[5]}$. A simpler system - if possible one single reliable prognostic marker - is an important requirement. Of the single tests currently in use, serum C-reactive protein (CRP) is the most popular and widely available marker of severity of acute pancreatitis in use today ${ }^{[6],[7],[8],[9]}$. It is costeffective and routinely available. Fluctuations in plasma are detectable by 6 hours, peak at 48 hours and persist with continuing inflammation. The present study was prospectively conducted to assess the relative value of serum $\mathrm{C}$-reactive protein and Ranson's scoring systems at the early stage of acute pancreatitis in identifying patients likely to develop complications. This study is conducted to assess the role of a simple, readily available, inexpensive parameter in predicting severity in acute pancreatitis when compared to the expensive and cumbersome multiple factor scoring system like Ranson's.

\section{Objectives}

1. To assess the relative accuracy of serum Creactive protein and Ranson's scoring system in predicting the severity of acute pancreatitis.

2. To evaluate the accuracy of serum C-reactive protein in monitoring the clinical course of the disease.

\section{Materials and Methods \\ Definitions in this study}

Mild acute pancreatitis (MAP) was defined according to the Atlanta classification as confirmed acute pancreatitis without development of one or more major local or systemic complications caused by pancreatitis.

Severe acute pancreatitis (SAP) was defined as acute pancreatitis associated with one or more major local or systemic complications caused by pancreatitis. Local complications include pancreatic necrosis, acute pancreatic fluid collection, pancreatic pseudocyst, or pancreatic abscess. Systemic complications include respiratory failure (pO2 $<60 \mathrm{~mm} \mathrm{Hg}$ requiring oxygen therapy for longer than 24 hours or mechanical ventilation), shock (systolic blood pressure $<80 \mathrm{~mm} \mathrm{Hg}$ for more than 15 minutes), renal failure (serum creatinine $>2$ $\mathrm{mg} \%$ in the absence of prior renal insufficiency), or the presence of gastrointestinal haemorrhage. Bacteria negative sepsis was defined as the systemic inflammatory response syndrome (SIRS) without positive blood culture. Sepsis was defined as blood culture positive SIRS. Death was considered as a complication.

\section{Patients}

All patients admitted with a diagnosis of acute pancreatitis in the general surgical wards were included in the study. Acute pancreatitis was initially diagnosed in all these patients on the basis of a serum amylase value of more than three times the normal (normal range 70-300 units /1) and a compatible clinical picture. A total of 42 patients were studied.

\section{Exclusion Criteria}

1) Abdominal disorders with similar clinical manifestations including perforated peptic ulcer, intestinal obstruction and abdominal malignancies were excluded.

2) All patients with a history of chronic pancreatitis (i.e. acute exacerbation of chronic pancreatitis) were excluded.

3) Also excluded were pregnant women, women on oral contraceptive pills or intrauterine devices since all these factors can alter CRP values.

The study was performed according to local ethics committee regulations and informed consent was obtained. 


\section{Methods}

After admission, all patients were clinically assessed periodically; blood was drawn for assessing Ranson's scoring system (Table 1), serum CRP estimation and other routine basic laboratory investigations. Serum CRP was assayed on the first, second, fourth and seventh day of admission. CRP was estimated by latex agglutination assay using Rhelax CRP reagent. Ultrasound of the abdomen was performed in all cases. CT scan of the abdomen was done in indicated cases.

The clinical course of the disease was studied. All patients were followed up till discharge or any untoward event like death. The patients were categorized as mild or severe with the available information using clinical assessment, Ranson's scoring system and serum CRP assays. A value of CRP> $150 \mathrm{mg} / \mathrm{L}$ within the first 48 hours was considered as a suitable cut-off ${ }^{5}$ for severity prediction. Similarly, Ranson's score $\geq 3$ was applied to predict severe prognosis.

All results were expressed as mean \pm standard deviation. $\mathrm{Z}$ test of significance was applied to calculate the statistical significance. The correlation between serum CRP and Ranson's score was evaluated by linear regression. The accuracy of both scoring modalities in correctly predicting proportion of patients as either mild or severe was assessed by using the formula given below.

\begin{tabular}{c|cc}
\hline Scoring system & \multicolumn{2}{|c}{ Actual outcome } \\
\hline Prediction & Severe & Mild \\
\hline Severe & a (true positive) & b (false positive) \\
Mild & c (false negative) & d (true negative \\
\hline
\end{tabular}

True positive- where the test predicts severe AP and outcome too is severe.

False positive- where the test predicts severe AP, but outcome is mild.

True negative- where the test predicts mild AP and the outcome is mild.

False negative- where the test predicts mild AP, but outcome is severe.

Sensitivity $=a /(a+c) \times 100$

Specificity $=d /(b+d) \times 100$

Positive predictive value $(P P V)=a /(a+b) \times 100$

Negative predictive value $(\mathrm{NPV})=\mathrm{d} /(\mathrm{c}+\mathrm{d}) \times 100$

Accuracy of the test $=(a+d) /(a+b+c+d) \times 100$

\section{Results}

A total of 42 patients with acute pancreatitis were studied (Table 1). The mean age of presentation was 42 years (range 18- 65) with males $(85.7 \%)$, far outnumbering the females. The male to female ratio was found to be $6: 1$; whereas in the West, the ratio is close to unity or there is slight female preponderance $^{[10]}$. The average age of males was 40.27 years and that of females was 43.83 years. The maximum number of patients was found in the age-group 31- 40 years; 14 patients (33.3\%) were in this age- group. This is in sharp contrast with Western studies ${ }^{[10]}$, where acute pancreatitis is usually seen in the sixth decade.

Thirty patients suffered from mild acute pancreatitis (MAP) and 12 from severe acute pancreatitis (SAP) in this study. Out of 30 cases of MAP, 26 were males, and 4 were females. The age-range was 18 58 years; with the average age of males being 37.53 years and that of females being 40.75 years. Of the 12 cases of SAP, 10 were males, and, 2 females. The age-range here was 39- 65 years; the average age of males was 47.4 years and that of females was 50 years.

Alcohol constitutes the major cause of acute pancreatitis in our study $(80 \%)$, the second being gallstones $(10 \%)$. In the remaining, the cause was unknown. In the 30 patients with MAP, the aetiology was alcoholic in 24 cases (80\%), gallstones in 4cases (13\%), unknown in 2 cases (7\%). In SAP, out of 12 patients, the etiology was alcoholic in 10 cases $(83 \%)$, unknown in 2 cases (17\%).

Ranson's scoring system (Table 5):

- When Ranson's score of $\geq 3$ was taken as severe, 16 patients were predicted to have severe pancreatitis.

- Of the 16 , only 8 patients turned out to have a severe outcome.

$$
\begin{aligned}
& \text { Sensitivity }=66.6 \% \\
& \text { Specificity }=73.3 \% \\
& \text { PPV }=50 \% \\
& \text { NPV }=78.5 \% \\
& \text { Accuracy }=71.4 \% .
\end{aligned}
$$




\section{Serum CRP:}

- When serum CRP with a value of $150 \mathrm{mg} / \mathrm{L}$ is used as cut-off, 14 patients were considered severe. (Table 5)

- Of the 14 patients, 10 cases turned out to have a severe outcome.

$$
\begin{array}{ll}
\text { Sensitivity } & =83.3 \% \\
\text { Specificity } & =86.6 \% \\
\text { PPV } & =71 \% \\
\text { NPV } & =92.8 \% \\
\text { Accuracy } & =85.7 \%
\end{array}
$$

\section{Severity prediction and accuracy}

The correlation coefficient between CRP and Ranson's score gave a $\mathrm{P}$ value of, $\mathrm{P}<0.05$. This was found to be statistically significant. The overall prognostic sensitivity, positive predictive value and accuracy of serum CRP were significantly higher when compared to the Ranson's scoring system.

CRP level remained elevated on day 7 in four patients, who later developed late complications like pseudocysts. CRP remained elevated throughout the observation period in SAP but not in MAP. The fall of CRP level towards normal was delayed in severe cases.

Mortality rate: Four out of the 12 cases with severe outcome expired. The mortality rate overall was $9.5 \%$ and in the SAP group alone, it was $33.3 \%$. Four patients died: two from severe shock, and two after emergency laparotomy for necrotizing acute pancreatitis.

Table 1 Ranson's Criteria

\begin{tabular}{c} 
On admission: \\
Age $>55$ years \\
Blood glucose $>200 \mathrm{mg} / \mathrm{dl}$ \\
WBC count $>16000$ \\
$\mathrm{LDH}>350 \mathrm{IU} / \mathrm{l}$ \\
$\mathrm{AST}>250 \mathrm{IU} / \mathrm{l}$ \\
Within 48 hours: \\
Decrease in Hematocrit $>10 \%$ \\
Increase in BUN $>5 \mathrm{mg} / \mathrm{dl}$ \\
Serum Ca2+<8 mg/dl \\
Fluid sequestered $>6 \mathrm{litres}$ \\
PaO2 $<60 \mathrm{~mm}$ of Hg \\
Base deficit $>4$ mmol/l \\
\hline WBC, white blood cell count \\
LDH, lactate dehydrogenase \\
AST, aspartate transaminase
\end{tabular}

Table 2 Patient Profile

\begin{tabular}{lcc} 
Patient characteristics & $\begin{array}{c}\text { No. of } \\
\text { cases }\end{array}$ & Percentage \\
\hline Sex & 36 & 85.7 \\
Male & 6 & 14.3 \\
Female & & \\
& & \\
Age group & 2 & 4.7 \\
11- 20 & 8 & 19 \\
$21-30$ & 14 & 33.33 \\
31- 40 & 10 & 24 \\
41-50 & 7 & 16.6 \\
51-60 & 1 & 2.4 \\
61-70 & & \\
Aetiology of AP & 34 & 81 \\
Alcohol & 4 & 9.5 \\
Biliary & 4 & 9.5 \\
Unknown & & \\
& & \\
Severity of AP & 30 & 71 \\
Mild & 12 & 29 \\
Severe & & \\
Mortality & 4 & 9.5 \\
Overall & 4 & \\
In severe AP group & & \\
\hline
\end{tabular}

Table 3 Severe Acute Pancreatitis

\begin{tabular}{lc} 
Complications & No. of cases \\
\hline Pseudocysts & 4 \\
$\begin{array}{l}\text { Necrotizing pancreatitis } \\
\text { (required laparotomy) }\end{array}$ & 2 \\
Shock & 2 \\
Acute respiratory insufficiency & 2 \\
Acute renal failure & 1 \\
Septicaemia & 1 \\
\hline
\end{tabular}

Table 4 Prognostic stratification

\begin{tabular}{c|c|c}
$\begin{array}{c}\text { Ranson's } \\
\text { Scoring } \\
\text { system }\end{array}$ & \multicolumn{2}{|c}{ Actual outcome } \\
\hline Prediction & Severe & Mild \\
Severe & 8 (true positive) & 8 (false positive) \\
Mild & 4 (false negative) & 22 (true negative) \\
Serum CRP & Actual outcome \\
\hline Prediction & Severe & Mild \\
Severe & 10 (true positive) & 4 (false positive) \\
Mild & 2 (false negative) & 26 (true negative) \\
\hline
\end{tabular}

Table 5 Comparison of CRP and Ranson's criteria for prediction of severe pancreatitis

\begin{tabular}{lcccc} 
Criteria & $\begin{array}{c}\text { Cut- } \\
\text { off } \\
\text { value }\end{array}$ & $\begin{array}{c}\text { Sensitivity } \\
(\%)\end{array}$ & $\begin{array}{c}\text { Specificity } \\
(\%)\end{array}$ & $\begin{array}{c}\text { Accuracy } \\
(\%)\end{array}$ \\
\hline CRP(mg/L) & 150 & 83.3 & 86.6 & 85.7 \\
Ranson's & $\geq 3$ & 66.6 & 73.3 & 71.4 \\
score & & & & \\
\hline
\end{tabular}


Table 6 Comparison of Ranson's scoring system amongst different studies (all values in percentage)

\begin{tabular}{l|c|c|c|c|c}
\hline $\begin{array}{l}\text { Ranson's } \\
\geq 3\end{array}$ & $\begin{array}{c}\text { Sensit } \\
\text { ivity }\end{array}$ & $\begin{array}{c}\text { Specific } \\
\text { ity }\end{array}$ & PPV & NPV & $\begin{array}{c}\text { Accura } \\
\text { cy }\end{array}$ \\
\hline $\begin{array}{l}\text { Wilson } \text { et } \\
a l^{12} \text {. }\end{array}$ & 87 & 71 & 49 & 94 & 75 \\
$\begin{array}{l}\text { Larvin et } \\
a l^{4} \text {. }\end{array}$ & 75 & 68 & 37 & 91 & 69 \\
$\begin{array}{l}\text { Khanna } e \\
t a l^{20}\end{array}$ & 83.9 & 78 & 74.3 & 86.5 & 80.6 \\
$\begin{array}{l}\text { Our } \\
\text { Study }\end{array}$ & 66.6 & 73.3 & 50 & 78.5 & 71.4 \\
\hline
\end{tabular}

Table 7 Comparison of studies on CRP as severity predictor in acute pancreatitis (all values in percentage)

\begin{tabular}{l|c|c|c}
\hline CRP & Sensitivity & Specificity & Accuracy \\
\hline Wilson et al & 83 & 85 & 85 \\
Chen et $a l^{19}$ & 94 & 76 & 82 \\
Khanna et $_{\text {al }}{ }^{20}$ & 86.2 & 100 & 93.3 \\
Our Study & 83.3 & 86.6 & 85.7 \\
\hline
\end{tabular}

\section{Discussion}

The search for an ideal objective marker of severity in acute pancreatitis continues. For many years the best prediction of severity has been achieved by the multifactorial scoring systems. These scoring systems were not designed to monitor the course of the disease. Nevertheless, they have gained widespread acceptance. The best accuracy that has been achieved with these systems is the order of 75$80 \%{ }^{[11]}$, which implies that in one-fifth to one quarter of patients the prediction will be incorrect. The accuracy rate for Ranson's in our study is $71.4 \%$. One of the disadvantages of this system is that these criteria do not allow for prediction until 48 hours into the course of the disease. Thus they amount to a one-time prognostic "snapshot" after an initial delay that some consider a missed opportunity for therapy. For many patients with intermediate scores, clinical decision-making is more difficult. Thus, although Ranson's scoring system has been widely applied, its complexity limits its use in clinical practice.

\section{Serum CRP}

In our study, serum CRP done on day 2 or day 4 has revealed itself to be a useful predictor of severity and complications in acute pancreatitis. The CRP level reached its peak around the second to fourth day of the illness. The cut-off value for serum CRP, used in our study was $150 \mathrm{mg} / \mathrm{L}$. Wilson et al ${ }^{[12]}$. found that peak CRP (on day 2,3 or 4 ) $\geq 210 \mathrm{mg} / \mathrm{L}$ provides the best discrimination of complicated attacks. A recent consensus agreed that a value of CRP > $150 \mathrm{mg} / \mathrm{L}$ within the first 48 hours of symptoms was a suitable cut-off for severity prediction $^{5}$. In this study, CRP levels showed the best discrimination between mild and severe disease when compared to the Ranson's scoring system. CRP is a proven predictor of severity for acute pancreatitis when serum level over $150 \mathrm{mg} / \mathrm{L}$ is measured within 48 hours after the onset of symptoms ${ }^{[13],[14]}$. A cut-off level of $150 \mathrm{mg} / \mathrm{L}$ within the first $48 \mathrm{hrs}$ of symptom onset has sensitivity and specificity of $80-86 \%$ and $61-84 \%$, respectively, for SAP and accuracy $>80 \%$ for necrotizing pancreatitis ${ }^{[15]}$. Neoptolemos et $a l^{[16]}$ have also found that CRP concentrations were significantly different between mild and severe pancreatitis cases at 48 hours, but not at 24 hours. The sensitivity and the positive predictive values of serum CRP levels in patients with severe pancreatitis have been reported to be 83 to $100 \%$, and 37 to $77 \%$, respectively ${ }^{[17]}$.

Mayer et $a l^{[18]}$ reported that the risk of developing pancreatic collections is high when the CRP values remain high $(\geq 100 \mathrm{mg} / \mathrm{L})$ at the end of the first week of illness. Similar observations were noted in our study when four of our patients with elevated CRP levels at the end of first week, developed pseudocysts later on. Thus CRP value on day 7 was also useful in monitoring the clinical course. Also, the fall of CRP level towards normal was delayed in severe cases in our study. Moreover, the CRP assay is simple, quick to perform, inexpensive, provides useful clinical information and is found to be more adaptable for routine clinical practice than multiple factor scoring systems.

\section{Conclusion}

This study suggests that serum CRP as a single parameter can be used to predict the development of 
complications in acute pancreatitis. C-reactive protein is a good early marker for the severity of acute pancreatitis. CRP appears to be predictive of pancreatic complications in addition to predicting systemic complications. Serum CRP shows a higher prognostic sensitivity and accuracy than Ranson's scoring system. When compared to Ranson's system, CRP is more valuable in the assessment of severity of acute pancreatitis. The high increased levels at the beginning point to serious course of disease in future. A high CRP level persisting in the first week of admission, calls for an intensive search for pancreatic collection or other complications especially in those with initial mild clinical course. The CRP value at the end of the first week is useful in monitoring the clinical course. Moreover, CRP is a simple and inexpensive parameter, whereas Ranson's criteria are expensive and cumbersome.

\section{References}

1. Banks PA, Freeman ML, Practice Parameters Committee of the American College of Gastroenterology. Practice guidelines in acute pancreatitis. Am $\mathbf{J}$ Gastroenterol. 2006;101:2379-400.

2. van Dijk SM, Hallensleben NDL, van Santvoort HC, et al. Acute pancreatitis: recent advances through randomised trials. Gut. 2017;66:2024-32.

3. Banks PA. Predictors of severity in acute pancreatitis. Pancreas 1991; 6(suppl): S712.

4. Larvin M, McMahon M. APACHE-II score for assessment and monitoring of acute pancreatitis. Lancet 1989;22:201-205.

5. Dervanis et al. Consensus document: diagnosis, objective assessment of severity and management of acute pancreatitis. Int $J$ Pancreatol 1999; 25: 195-210.

6. Sandberg AA, Borgström A. Early prediction of severity in acute pancreatitis. Is this possible? JOP 2002; 3: 116-125.

7. Neoptolemos JP, Kemppainen EA, Mayer JM, Fitzpatrick JM, Raraty MG, Slavin J et al. Early prediction of severity in acute pancreatitis by urinary trypsinogen activation peptide: a multicentre study. Lancet 2000; 355: 1955-1960.

8. Wilson C, Heath DI, Imrie CW. Prediction of outcome in acute pancreatitis: a comparative study of APACHE II, clinical assessment and multiple factor scoring systems. Br J Surg1990; 77: 1260-1264.

9. Wilson C, Heads A, Shenkin A, Imrie CW. $C$ - reactive protein, antiproteases and complement factors as objective markers of severity in acute pancreatitis. Br J Surg1989; 76: 177-181.

10. Fan S, Choi TK, Lai CS, Wong J. influence of age on the mortality from acute pancreatitis. Br J Surg 1988; 75:463.

11. Simon K. Toh, Colin D. Johnson. Recent Advances in Surgery 21, Severity prediction in acute pancreatitis. 125- 136.

12. Wilson C, Heads A, Shenkin A, Imrie C. Creactive protein, antiproteases and complement factors as objective markers of severity in acute pancreatitis. $\mathrm{Br} J$ Surg 1989;76:177-181.

13. Robert JH, Frossard JL, Mermillod B, Soravia C, Mensi N, Roth M, et al. Early prediction of acute pancreatitis: prospective study comparing computed tomography scans, Ranson, Glasgow, acute physiology and chronic health evaluation II scores and various serum markers. World J Surg 2002; 26:612-9. [PMID 12098056]

14. Yadav D, Agarwal N, Pitchumoni CS. A critical evaluation of laboratory tests in acute pancreatitis. Am J Gastroenterol 2002; 97:1309-18. [PMID 12094843]

15. Neoptolemos JP, Kemppainen EA, Mayer $\mathrm{JM}$, et al. Early prediction of severity in acute pancreatitis by urinary trypsinogen activation peptide: a multicentre study. The Lancet. 2000;355(9219):1955-1960.

16. Neoptolemos JP, Kemppainen EA, Mayer JM, Fitzparrick JM, Raraty MG, Slavin J, et al. Early prediction of severity in acute pancreatitis by urinary trypsinogen 
activation peptides: A multicenter study.

Lancet 2000; 355:1955-60. [PMID 10859041]

17. Triester SL, Kowdley KV. Prognostic factors in acute pancreatitis. J Clin Gastroenterol 2002; 34:167- 76. [PMID 11782614]

18. Mayer AD, McMahon MJ, Bowen $\mathrm{M}$ et al. C-reactive protein: an aid to assessment and monitoring of acute pancreatitis. J Clin. Pathol. 1984; 34: 207-11.

19. CC Chen, SS Wang, Y Chao, CW Lu, SD Lee. YT Tsai, KJ Lo et al.C-reactive protein and lactate dehydrogenase isoenzymes in the assessment of the prognosis of acute pancreatitis. J Gastroenterol Hepatol, 1992; 7: 363-366.

20. Khanna AK, Meher S, Prakash S, Tiwary SK, Singh U, Srivastava A, et al. Comparison of Ranson, Glasgow, MOSS, SIRS, BISAP, APACHE-II, CTSI Scores, IL-6, CRP, and Procalcitonin in predicting severity, organ failure, pancreatic necrosis, and mortality in acute pancreatitis. HPB Surg 2013. 2013367581. 